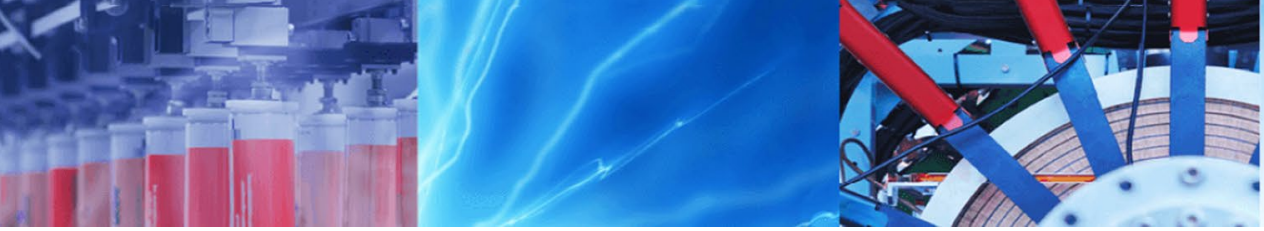

Research Article

\title{
Improving the proton conductivity of graphene oxide membranes by intercalating cations
}

\author{
Nur Laila Hamidah ${ }^{1,2}$ (1) $\cdot$ Masataka Shintani ${ }^{1} \cdot$ Aynul Sakinah Ahmad Fauzi $^{1} \cdot$ Elaine G. Mission $^{1}$ (1) \\ Kazuto Hatakeyama ${ }^{3}$ (D) Armando T. Quitain ${ }^{4}$ (D) Tetsuya Kida ${ }^{5}$
}

(c) Springer Nature Switzerland AG 2019

\begin{abstract}
Graphene oxide (GO) membrane has gained increasing attention because of its extraordinary physical and chemical properties and high proton conductivity. GO is rich in oxygenated functional groups, which can support proton transportation. However, pristine $\mathrm{GO}$ is unstable at high temperatures due to the removal of oxygen functional groups, resulting in a decrease in the interlayer distance of stacked GO nanosheets. Hence, we propose a modification of GO membranes via the intercalation of cations to enhance the proton conductivity. Modified self-standing $\mathrm{GO}$ membranes with $\mathrm{Al}^{3+}$ and $\mathrm{La}^{3+}$ were fabricated by a vacuum filtration method. They exhibited a larger distance of the interlayer that serves as proton hopping pathways. Furthermore, the modified GO membrane showed a higher proton conductivity than a pristine GO membrane even at $80^{\circ} \mathrm{C}$, as confirmed by Electrochemical Impedance Spectroscopy. The results demonstrate that intercalating cations in between $\mathrm{GO}$ nanosheets is effective in improving the practical feasibility of proton conducting GO membranes.
\end{abstract}

Keywords Graphene oxide membranes · Cations · Proton conductivity · Thermal stability

\section{Introduction}

Graphene oxide (GO) is a 2D material characterized with the honeycomb molecular structure. GO has gained increasing attention because of its remarkable physical, chemical and electronic properties [1]. GO contains various oxygenated functional groups such as hydroxyl, epoxy, carbonyl, and carboxyl groups. It has found potential applications in super-capacitors [2-4], catalysts [5-7], and proton conducting membranes in fuel cell or water electrolysis [8-11]. It was recently demonstrated that GO shows good proton conductivities that are comparable to that of Nafion. Epoxide groups on GO surface is considered to mainly serve as proton hopping sites $[8,12,13]$.

However, GO has a tendency to lose surface functionalities even at slightly elevated temperatures. As the oxygenated functionalities detach from the carbon backbone, the interlayer distance in between stacked GO nanosheets decreases, leading to a decrease in proton conduction. Thus, maintaining the proton conductivity of $\mathrm{GO}$ at high temperatures is quite a challenge. In order to address this concern, GO membranes could be

Electronic supplementary material The online version of this article (https://doi.org/10.1007/s42452-019-0641-y) contains supplementary material, which is available to authorized users.

$\triangle$ Nur Laila Hamidah, nurlaila.hamidah88@gmail.com; $\bowtie$ Tetsuya Kida, tetsuya@kumamoto-u.ac.jp| ${ }^{1}$ Department of Applied Chemistry and Biochemistry, Graduate School of Science and Technology, Kumamoto University, Kumamoto 860-8555, Japan. ${ }^{2}$ Department of Engineering Physics, Institut Teknologi Sepuluh Nopember, Surabaya 60111, Indonesia. ${ }^{3}$ Nanomaterials Research Institute, Department of Materials and Chemistry, National Institute of Advanced Industrial Science and Technology (AIST), Tsukuba 305-8565, Japan. ${ }^{4}$ College of Cross-Cultural and Multi Discipline Studies, Kumamoto University, Kumamoto 860-8555, Japan. ${ }^{5}$ Division of Materials Science, Faculty of Advanced Science and Technology, Kumamoto University, Kumamoto 860-8555, Japan.

SN Applied Sciences (2019) 1:630 | https://doi.org/10.1007/s42452-019-0641-y

Received: 25 November 2018 / Accepted: 19 May 2019 / Published online: 24 May 2019 
modified through the introduction of cations. Several cations, such as $\mathrm{Na}^{+}, \mathrm{Mg}^{2+,} \mathrm{Ca}^{2+}$ and $\mathrm{Al}^{3+}$ have already been successfully applied in modifying $\mathrm{GO}$ in order to enhance the membrane stability in aqueous solution for desalination and separation applications [14-17]. These cations would form ionic interaction with the negatively charged GO nanosheets. Amirov et al. [18, 19] reported that carboxyl groups in $\mathrm{GO}$ behave as ligands, which bind to metal cations via chemical bonding.

This study focused on the intercalation of the lanthanum cation $\left(\mathrm{La}^{3+}\right)$ in between stacked GO nanosheets. $\mathrm{La}^{3+}$-based materials have been considered as an attractive material for electrochemical-based systems [20-22]. We studied the effect of $\mathrm{La}^{3+}$ and $\mathrm{Al}^{3+}$ intercalation on the proton conductivity of GO membranes by an EIS technique and examined the correlation between proton conductivity and physicochemical properties.

\section{Experimental section}

\subsection{Synthesis of GO and membrane fabrication}

GO was prepared from synthetic graphite powder (Wako Pure Chemical Industries, Osaka, Japan) following the modified Hummers' method. The detailed procedure has already been reported elsewhere [23, 24]. Briefly, graphite was first oxidized into graphite oxide with sulfuric acid and potassium permanganate. The oxidized graphite was cooled and recovered from liquid by centrifugation at $4000 \mathrm{rpm}$ for $30 \mathrm{~min}$. The precipitates were then washed with a $\mathrm{HCl}$ aqueous solution (5\%) by centrifugation at $4000 \mathrm{rpm}$ for 30 min three times to remove $\mathrm{K}^{+}$and $\mathrm{Mn}^{+}$. The solid products were washed with distilled water by centrifugation at $4000 \mathrm{rpm}$ for $30 \mathrm{~min}$ three times. Graphite oxide was ultrasonicated for $5 \mathrm{~h}$ to obtain GO nanosheets, which were redispersed in distilled water to make a GO dispersion. Subsequently, $0.01 \mathrm{mmol}$ of aluminum nitrate $\left[\mathrm{Al}\left(\mathrm{NO}_{3}\right)_{3},>98.0 \%\right.$, Chameleon reagent under Kishida Kagaku, Japan) and lanthanum nitrate [ $\mathrm{La}\left(\mathrm{NO}_{3}\right)_{3}$, Wako Pure Chemical Industries, Osaka, Japan] were separately added into the GO dispersion. The mixed solution of $\mathrm{GO}$ and cation was poured onto membrane filters $(180 \mu \mathrm{m}$ and $0.4 \mu \mathrm{m}$ membrane filter stacked together). Then, the system was subjected to vacuum filtration at room temperature and atmospheric pressure. A self-standing membrane formed was separated from the supporting membrane filters. The final concentration of the intercalated cations was estimated through the mass differences between pristine GO and modified $\mathrm{GO}$ membranes. The thickness of the membranes was $180 \mu \mathrm{m}$.

SN Applied Sciences

\subsection{Materials characterization}

The structure and interlayer spacing in between GO nanosheets of the fabricated GO membrane were characterized by X-ray diffraction (XRD; MiniFlex600, Rigaku) with Cu Ka radiation $(\lambda=0.154 \mathrm{~nm}, \mathrm{U}=40 \mathrm{kV}$ and $\mathrm{I}=15 \mathrm{~mA}$ ) in the $2 \theta$ range of $5^{\circ}-45^{\circ}$. The morphology of $\mathrm{GO}$ nanosheets was observed by scanning electron microscopy (SEM; JSM7600F, JEOL) and atomic force microscopy (AFM). The size distribution of the GO nanosheets was examined with a DLS spectrophotometer (Zetasizer Nano ZS, Malvern Instruments). The presence of oxygen functional groups was analyzed using a Fourier transform infrared (FT-IR) spectrometer (FTIR 4100, JASCO) through the $\mathrm{KBr}$ pellet technique and X-ray photoemission spectroscopy (XPS; PHI 1600, PerkinElmer). Thermal stability of samples were examined by thermogravimetric-differential thermal analysis (TG-DTA; SII Exstar 6000, SEIKO) at 25 to $300^{\circ} \mathrm{C}$ with the heating rate of $10^{\circ} \mathrm{C} / \mathrm{min}$ under a constant nitrogen flow $(20 \mathrm{~mL} / \mathrm{min})$. The BET surface area was measured with a surface area analyzer (BELSORP-mini II, Microtrack Bell) under nitrogen atmosphere at $77 \mathrm{~K}$. For the pretreatment, samples were heated under $\mathrm{N}_{2}$ at $60^{\circ} \mathrm{C}$ for $24 \mathrm{~h}$.

\subsection{Proton and electrical conductivity measurement}

The proton conductivities of GO and modified GO membranes were measured by $A C$ impedance spectroscopy using an impedance analyzer (1260, Solartron) over the frequency range of $1 \mathrm{~Hz}$ to $1 \mathrm{MHz}$ with the test signal voltage of $100 \mathrm{mV}$. Platinum (Pt) was deposited onto the membrane surface as the electrodes using a sputtering technique. The membrane was placed in an incubator, and its impedance was measured at 25 to $80^{\circ} \mathrm{C}$. The electrical conductivity of the membrane was also measured by a two-probe DC method using a multimeter (33410A, Agilent).

The proton and electrical conductivities were calculated following Eq. 1,

$\sigma=\frac{l}{A \cdot R s}$

where $\sigma\left(\mathrm{S} \mathrm{cm}^{-1}\right)$ is the conductivity of the membranes, $\mathrm{I}(\mathrm{cm})$ is the membrane thickness, and $\mathrm{A}(\mathrm{cm})$ and $\mathrm{Rs}(\Omega)$ represent the cross section area and the resistances of the membranes measured by AC impedance spectroscopy as well as by a two probe DC method, respectively. A Nyquist plot was obtained using impedance values fitted based on the proposed equivalent circuit as depicted in Fig. 1, 


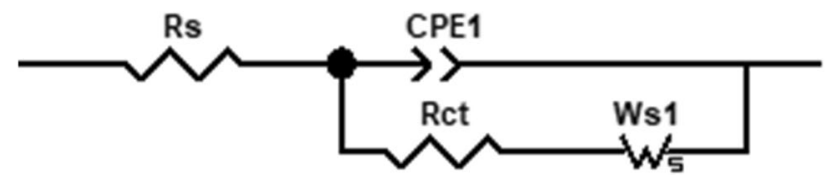

Fig. 1 Equivalent circuit of GO membranes

where Rs is the bulk resistance and CPE is the constant phase element employed to replace the capacitance (C) element to get the fitting result more precisely, while Rct and Ws 1 represent the charge transfer resistance and the Warburg impedance associated with ionic diffusion of the membrane [25-27], respectively.

\section{Result and discussion}

\subsection{GO membrane characterization}

The exfoliation of GO nanosheets was confirmed by SEM, DLS, and AFM analyses, as shown in Fig. S1 (supplementary materials). A representative SEM image shows a sheet-like structure of the sample. The thickness of GO nanosheets was estimated to be $1.1 \mathrm{~nm}$ by the AFM results. The presence of smaller GO nanosheets of 200 to $300 \mathrm{~nm}$ was mainly seen by DLS analysis. The surface area of GO was calculated to be $35 \mathrm{~m}^{2} / \mathrm{g}$ from the nitrogen adsorption/ desorption isotherm (Fig. S2), which was the type IV isotherm typically for mesoporous materials. The low $\mathrm{N}_{2}$ adsorption and low pore volumes indicate the intimate stacking of GO nanosheets. Figure 2 shows the XRD patterns of membranes made of pristine $\mathrm{GO}$ in comparison with those with $\mathrm{Al}^{3+}$ and $\mathrm{La}^{3+}$. All three XRD patterns

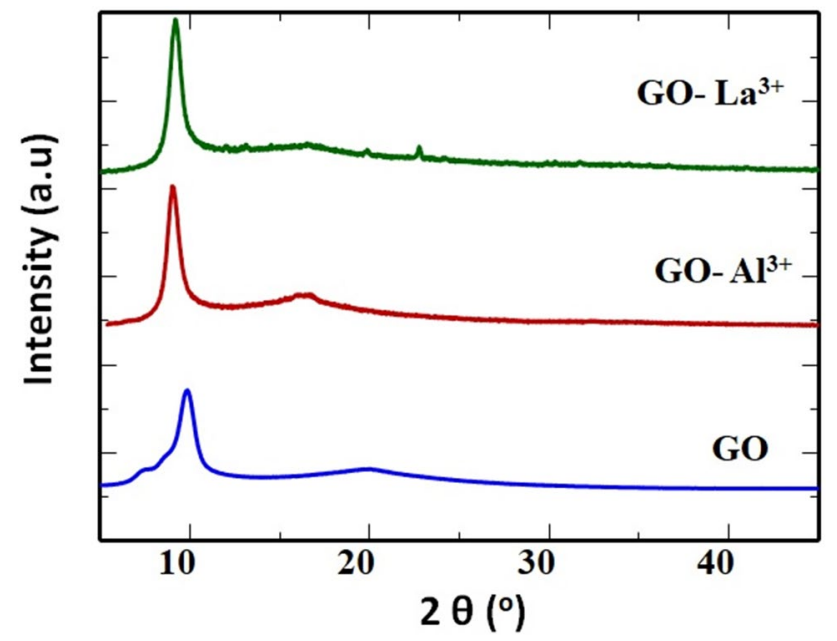

Fig. 2 XRD patterns of pristine GO and cation modified GO membranes showed a single sharp peak. The characteristic peak for the pristine GO membrane was observed at $2 \theta=9.4^{\circ}$, indicating the introduction of oxygen functional groups onto graphene sheets [28].The XRD peaks for $\mathrm{Al}^{3+}$ and $\mathrm{La}^{3+}$-modified GO membranes slightly shifted to a lower degree of $2 \theta=8.8^{\circ}$ and $7.9^{\circ}$, respectively. The shift could be an indication of the alteration in the crystallinity and interlayer structure of the GO membranes due to the presence of ionic interaction between oxygen functional groups and the cations. The interlayer spacing (d) was also found to change. The pristine $G O$ membrane has $d=9.4 \AA$ while $\mathrm{Al}^{3+}$ and $\mathrm{La}^{3+}$-modified $\mathrm{GO}$ membranes have $\mathrm{d}=10.3$ and $10.8 \AA$, respectively. Clearly, the intercalation of cations increased the interlayer spacing. The slight difference in d-spacing for $\mathrm{Al}^{3+}$ and $\mathrm{La}^{3+}$ could be attributed to the difference between their atomic radii. $\mathrm{La}^{3+}$ has a bigger atomic radius of $2.7 \AA$ than $\mathrm{Al}^{3+}$ with an atomic radius of $1.4 \AA$.

FTIR spectra of pristine $\mathrm{GO}$ and $\mathrm{Al}^{3+}$ and $\mathrm{La}^{3+}$-modified GO membranes are shown in Fig. 3. The broad peak between 3200 and $3700 \mathrm{~cm}^{-1}$ is regularly attributed to the presence of hydroxyl groups. It can be seen that there is no significant difference in hydroxyl functionalities for the three samples. The $\mathrm{C}=\mathrm{O}$ stretching vibration at $1725 \mathrm{~cm}^{-1}$ was maintained. However, for the $\mathrm{Al}^{3+}$ and $\mathrm{La}^{3+}$-modified $\mathrm{GO}$ membranes, a small peak at $1480 \mathrm{~cm}^{-1}$ was observed. This was previously ascribed to the formation of carboxylate chelates, for which carboxyl groups in GO should bind to $\mathrm{Al}^{3+}$ and $\mathrm{La}^{3+}$ [14]. The presence of oxygen functional groups was also confirmed by XPS analysis, as shown in Fig. S3. The oxygen content in GO was determined to be $57 \mathrm{wt} \%$.

We also estimated the amount of intercalated cations. On average, $\mathrm{Al}^{3+}$ amounted to $1.3 \pm 0.3 \mathrm{mg}$, i.e., about

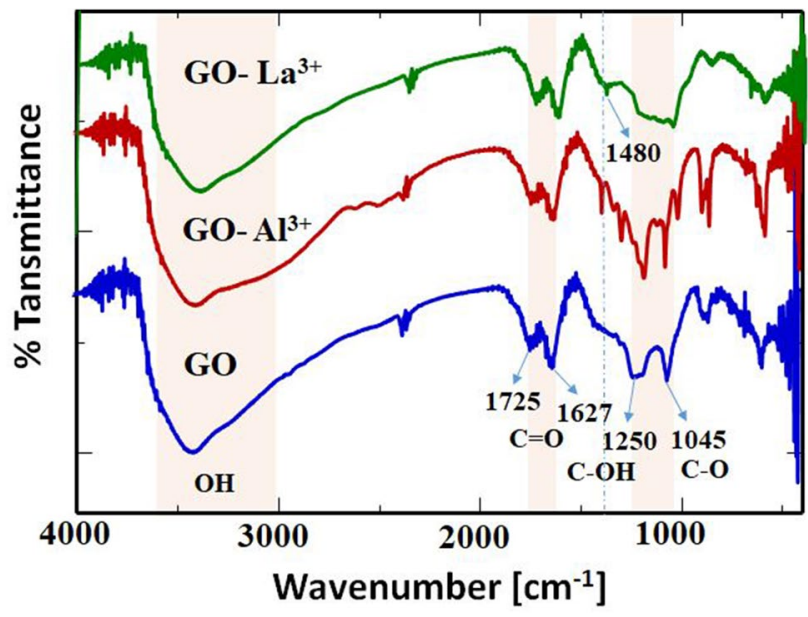

Fig. 3 FTIR spectra of pristine GO membrane and cation modified GO membranes 
8 wt $\%$ of the modified GO membrane. On the other hand, there was about $2.7 \pm 0.3 \mathrm{mg}$ of $\mathrm{La}^{3+}$ recorded, corresponding to $16 \mathrm{wt} \%$ of the modified GO membrane. The amount of $\mathrm{La}^{3+}$ contained is higher than that of $\mathrm{Al}^{3+}$. This might be due to the higher solubility of lanthanum nitrate in water (123-158 $\mathrm{g}$ per $100 \mathrm{ml})$ compared to that of aluminum nitrate with the solubility of $73.9 \mathrm{~g}$ per $100 \mathrm{ml}$. The higher amount of $\mathrm{La}^{3+}$ intercalated would contribute to the observed increase in the interlayer distance, as suggested by the XRD results.

\subsection{Electrochemical impedance spectroscopy (EIS)}

Electrochemical impedance spectroscopy (EIS) is the most reliable and effective technique to obtain the electrochemical characteristics of an electrochemical system [29]. We used an EIS technique to study the proton conduction in the GO membranes. ElS data were used to draw Nyquist plots that are represented in complex impedance plane consisting of real impedance $\left(Z^{\prime}\right)$ in $X$-axis and imaginary impedance $\left(Z^{\prime \prime}\right)$ in $Y$-axis. From the equivalent circuit depicted in Fig. 1, we expect that the Nyquist plots become a depressed semicircle representing the internal impedance of the GO membrane. Fig. 4 shows the Nyquist plots of the pristine $\mathrm{GO}$ membrane in comparison with those for $\mathrm{Al}^{3+}$ and $\mathrm{La}^{3+}$-modified $\mathrm{GO}$ membranes at varying temperatures. Depressed semicircles were generated for all the membranes. At the high frequency region (Fig. 4a inset), (1) the intersection between $\mathrm{X}$-axis and the starting point of the curve represents the sum of the membrane bulk resistance (Rs) and the contact resistance between the Pt electrode and a Pt mesh as a current collector and (2) the radius of the semicircles represents the charge transfer resistance of the electrode material [30]. The pristine GO membrane (Fig. 4a) showed a distinct semicircle at high frequency that corresponded to the double layer capacitance of the Pt electrode-membrane interface and the charge transfer resistance (Rct) [31]. A distinct capacitive semicircle was also generated for the $\mathrm{Al}^{3+}$-modified GO membrane. On the other hand, the membrane with $\mathrm{La}^{3+}$ showed a half capacitive semicircle that corresponded to a low charge transfer resistance.

The bulk resistance of the membranes increased as temperature increased. The pristine GO (Fig. 4a) membrane showed a bulk resistance (Rs) at around $1.5 \mathrm{k} \Omega$. However, at $80^{\circ} \mathrm{C}$, the Rs increased significantly and reached $9.1 \mathrm{k} \Omega$. When $\mathrm{Al}^{3+}$ was intercalated in between $\mathrm{GO}$ nanosheets, the Rs was lowered to $1.4 \mathrm{k} \Omega$ (Fig. 4b). The Rs was stable until $60^{\circ} \mathrm{C}$, but then it significantly increased at $80^{\circ} \mathrm{C}$. For the $\mathrm{La}^{3+}$-modified GO membrane (Fig. 4c), the maximum Rs was below $1 \mathrm{k} \Omega$. The Rs was almost stable even up to $80^{\circ} \mathrm{C}$. The resistance at high temperatures was almost
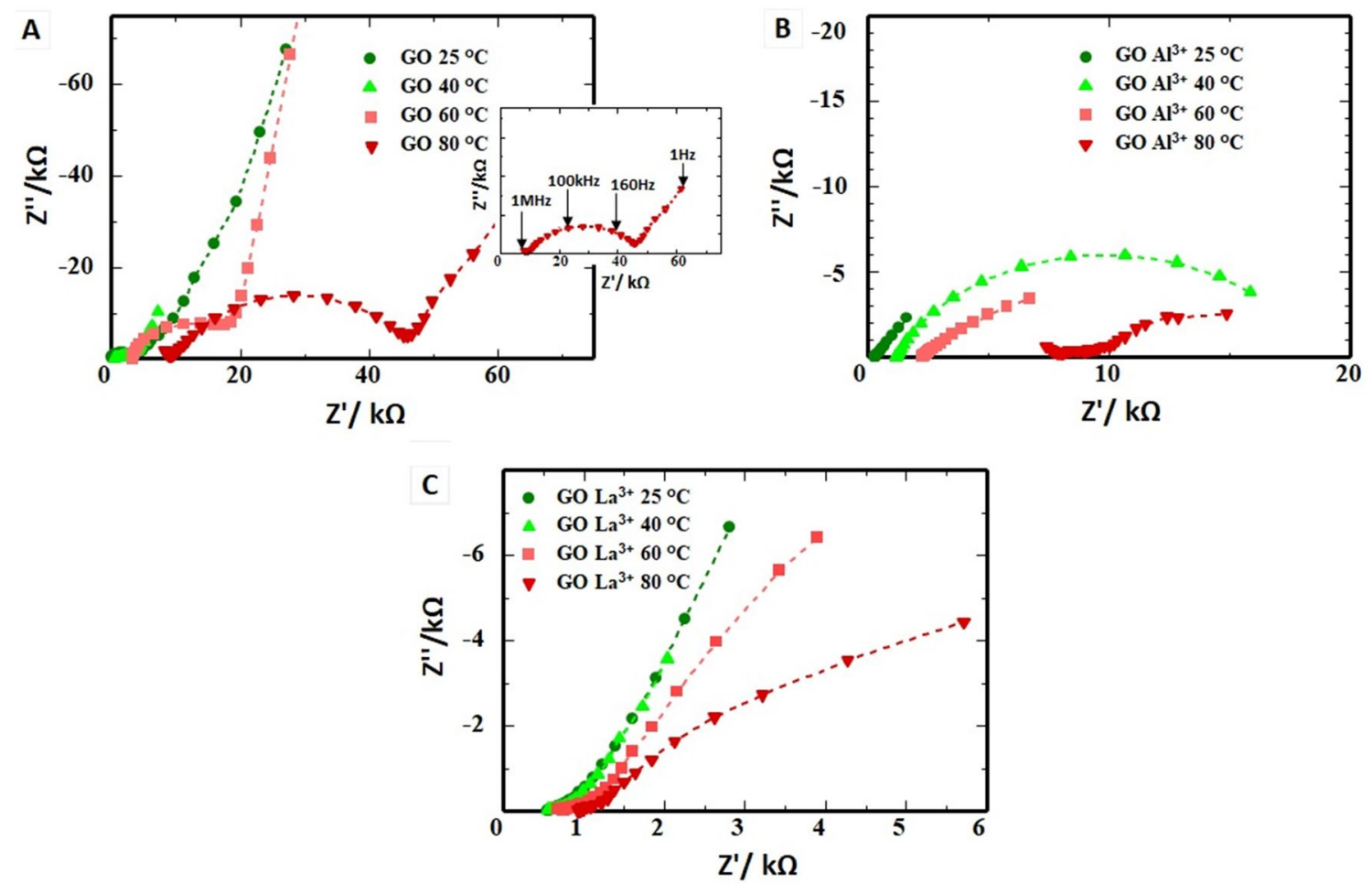

Fig. 4 Nyquist plots of GO membranes at different temperatures. a Pristine GO membrane, $\mathbf{b}$ modified GO membrane with 0.01 mmol of $\mathrm{Al}^{3+}$ and $\mathrm{c}$ modified GO membrane with $0.01 \mathrm{mmol}$ of $\mathrm{La}^{3}$ 
constant for the $\mathrm{La}^{3+}$-modified GO membrane, indicating its lower charge transfer resistance and bulk resistance even at high temperatures. At low frequency region, the slope of $45^{\circ}$ in Nyquist plots is denoted as the Warburg resistance that represents the ionic diffusion/transport in the membrane. The membrane with $\mathrm{La}^{3+}$ showed a $45^{\circ}$ slope at lower temperature, suggesting good ionic diffusion in $\mathrm{GO}$ [30]. In contrast, the $45^{\circ}$ slope at low frequency region was absent for the membrane with $\mathrm{Al}^{3+}$.

\subsection{Proton and electrical conductivity}

In Fig. 5, the temperature dependences of proton conductivity of the pristine, $\mathrm{Al}^{3+}$, and $\mathrm{La}^{3+}$-modified $\mathrm{GO}$ membranes are summarized. Pristine GO showed the lowest proton conductivity and its proton-conducting ability was found to decrease as temperature increased. The pristine

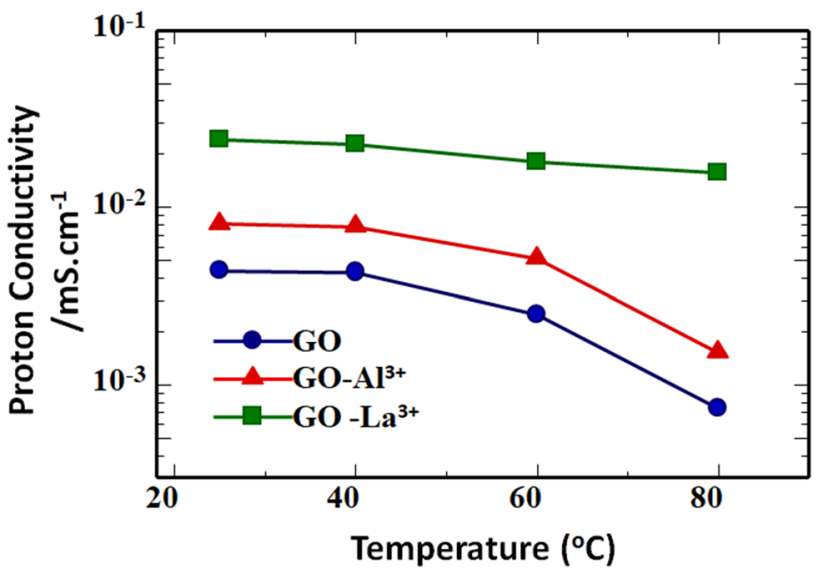

Fig. 5 Dependence of proton conductivity on temperature for the pristine and modified GO membranes. The relative humidity was $70 \%$
GO membrane losses oxygenated functional groups, leading to the loss of proton conduction, particularly at higher than $60^{\circ} \mathrm{C}$.

The loss in oxygen functional groups was confirmed by TG-DTA analysis, as depicted in Fig. 6, which showed that decreases in weight by 10 and $20 \%$ were noted at R.T. to 60 and 60 to $140{ }^{\circ} \mathrm{C}$, respectively. These losses were attributed to the removal of oxygen functional groups on GO. The complete combustion of pristine $\mathrm{GO}$ occurred at $150{ }^{\circ} \mathrm{C}$. On the contrary, both the $\mathrm{Al}^{3+}$ and $\mathrm{La}^{3+}$-modified $\mathrm{GO}$ membranes demonstrated much better proton conductivity than the pristine GO membrane. This demonstrates that the intercalation of cations indeed contributed to the improvement in proton conductivity. However, $\mathrm{Al}^{3+}$ still suffered a decline in proton conducting activity as temperature increased. On the other hand, the $\mathrm{La}^{3+}$-modified membrane maintained the superior proton conductivity compared with other membranes tested. One possible explanation is the enhanced hydration of the membrane with $\mathrm{La}^{3+}$ due to the larger interlayer spacing and the resulting efficient proton hopping in the interlayer. In addition, $\mathrm{La}^{3+}$ improved the stability of the membrane probably due to formation of cross links between GO nanosheets. An improvement in the thermal stability was confirmed by the TG-DTA results (Fig. 6). The TG curves showed that the weight loss due to removal of oxygen functional groups was suppressed by introducing $\mathrm{Al}^{3+}$ and $\mathrm{La}^{3+}$ in the interlayer. In addition, the presence of cations even suppressed the combustion of GO. A DTA peak due to the combustion of $\mathrm{GO}$ shifted from 140 to $175^{\circ} \mathrm{C}$ and $200{ }^{\circ} \mathrm{C}$ by $\mathrm{Al}^{3+}$ and $\mathrm{La}^{3+}$ cation introduction, respectively. The TG results indicate that the intercalated amounts of $\mathrm{Al}^{3+}$ and $\mathrm{La}^{3+}$ were 12 and 23\%, respectively. Intercalating $\mathrm{La}^{3+}$ with the larger amount in a GO membrane likely improved the thermal stability, leading to the higher proton conductivity.
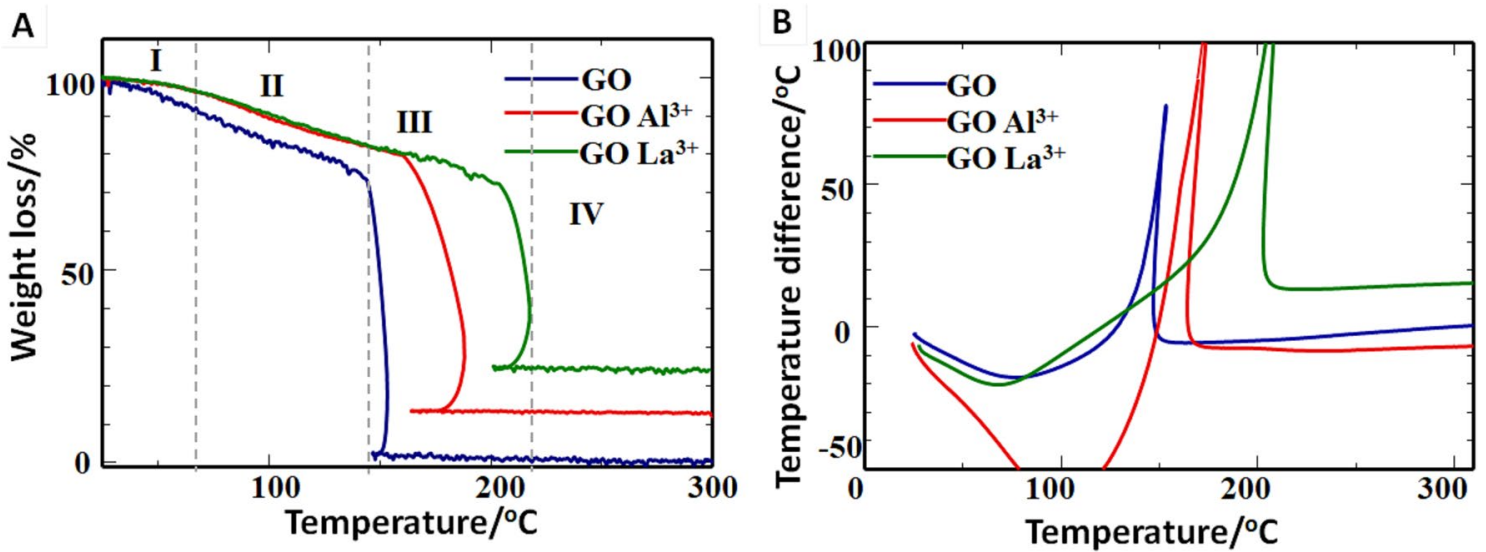

Fig. 6 a Thermogravimetric analysis (TGA) and $\mathbf{b}$ differential thermal analysis (DTA) curves of GO nanosheets in nitrogen atmosphere 
We also measured the electrical conductivity of the membranes. Figure 7 shows the temperature dependence of electrical conductivity of the pristine and modified GO membranes. At 25 and $40^{\circ} \mathrm{C}$, the electrical conductivity of all the membranes was low in the range of $R=0.5 \times 10^{-7}$ to $10^{-8} \mathrm{~S} / \mathrm{cm}$, making them pure solid electrolytes. However, the electrical conductivity of the membranes with cations significantly increased at more than $60^{\circ} \mathrm{C}$, while that for the pristine GO membrane remained low. The increase in the electrical conductivity can be explained by partial detachment of oxygen functional groups and the resulting increase in sp2-carbon regions in the membranes [32]. However, the detailed mechanism is not clear yet. Nevertheless, increasing the electrical conductivity while maintaining the high proton conductivity is favorable in terms of mixed proton-electron conduction, which would enable novel applications of GO such as electrocatalysts [12, 32].

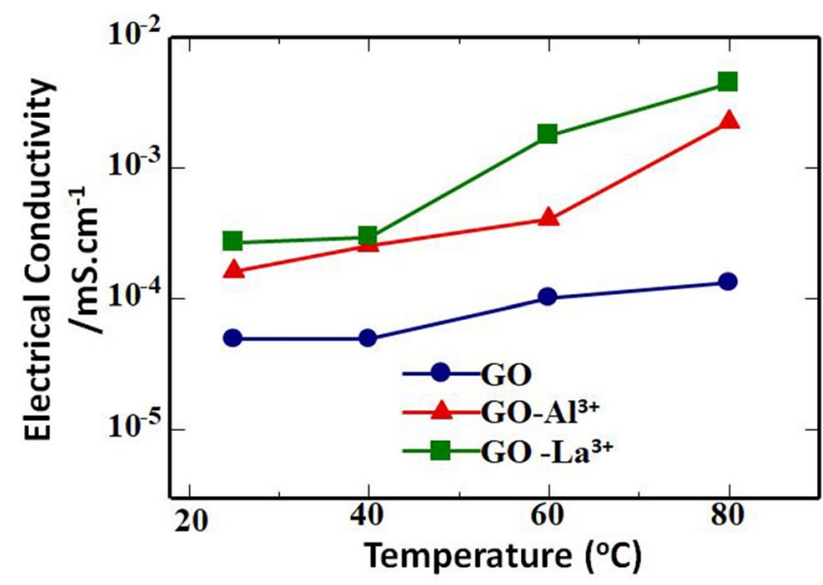

Fig. 7 Dependence of electrical conductivity on temperature for the pristine and modified GO membranes. The relative humidity was $70 \%$

\subsection{Post-treatment characterization of GO membranes}

The GO membranes after thermal treatment $\left(80^{\circ} \mathrm{C}\right)$ were characterized to clarify the correlation between conductivity and physicochemical properties of GO. The XRD and FTIR profiles collected are shown in Fig. 8a. The XRD peaks broadened and slightly shifted to the right. For instance, in the case of pristine $\mathrm{GO}$, it shifted from $2 \theta=9.4^{\circ}$ to $10.5^{\circ}$, corresponding to a decrease in $\mathrm{d}$-spacing. This is a typical characteristic of GO when it loses some oxygenated functionalities from its surface. The $d$-spacings are summarized in Table 1. After heat treatment, for pristine $\mathrm{GO}$ the $\mathrm{d}$-spacing decreased by as much as $20 \%$, while for $\mathrm{GO}-\mathrm{Al}^{3+}$ it decreased by $18 \%$. Interestingly, GO- $\mathrm{La}^{3+}$ only exhibited a $9 \%$ decrease in d-spacing. It is thus concluded that the smallest change in $\mathrm{d}$-spacing allowed the membrane with $\mathrm{La}^{3+}$ to maintain its stable proton conductivity even at high temperatures.

Changes in chemical structure of $\mathrm{GO}$ after thermal treatment $\left(80^{\circ} \mathrm{C}\right)$ were also examined by FTIR measurements, as depicted in Fig. 8b. After thermal treatment, the absorption peak at $3400 \mathrm{~cm}^{-1}$ that corresponded to $\mathrm{O}-\mathrm{H}$ group greatly decreased for pristine $\mathrm{GO}$ as well as $\mathrm{GO}$ with $\mathrm{Al}^{3+}$. In contrast, for $\mathrm{GO}$ with $\mathrm{La}^{3+}$ only a slight decrease was

Table 1 The interlayer distance of the pristine GO and modified GO membranes after heat treatment at $80^{\circ} \mathrm{C}$

\begin{tabular}{llllll}
\hline Cation types & \multicolumn{2}{l}{ Room temperature } & \multicolumn{2}{l}{$\begin{array}{l}\text { After high tempera- } \\
\text { ture treatment }\end{array}$} \\
\cline { 2 - 3 } \cline { 5 - 6 } & $2 \theta\left(^{\circ}\right)$ & d spacing $(\AA)$ & & $2 \theta\left(^{\circ}\right)$ & d spacing $(\AA)$ \\
\hline$G O$ & 9.4 & 9.4 & 10.5 & 7.5 \\
$\mathrm{GO}-\mathrm{Al}^{3+}$ & 8.8 & 10.3 & 9.9 & 8.4 \\
$\mathrm{GO}-\mathrm{La}^{3+}$ & 7.9 & 10.8 & 9.1 & 9.9 \\
\hline
\end{tabular}

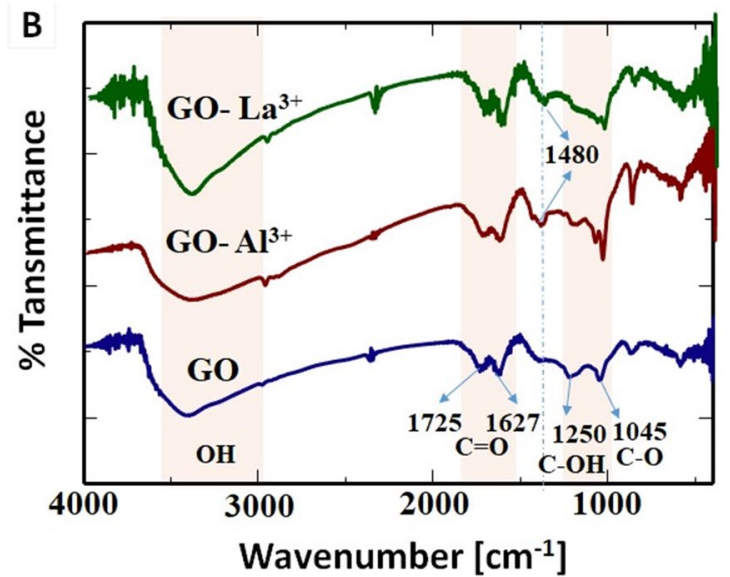

Fig. 8 a XRD patterns and $\mathbf{b}$ FTIR spectra of the pristine GO and modified GO membranes after heat treatment at $80^{\circ} \mathrm{C}$ 
observed. Furthermore, a decrease in absorption peak at 1725 and $1627 \mathrm{~cm}^{-1}$ ascribable to $\mathrm{C}=\mathrm{O}$ was seen for pristine $\mathrm{GO}$ and $\mathrm{GO}$ with $\mathrm{Al}^{3+}$. However, almost no change in $\mathrm{C}=\mathrm{O}$ peak was seen for $\mathrm{GO}$ with $\mathrm{La}^{3+}$. The FTIR results indicate that $\mathrm{GO}$ with $\mathrm{La}^{3+}$ maintained oxygen functional groups even after thermal treatment. The strong interaction of $\mathrm{La}^{3+}$ with oxygen functional groups may retard their desorption from $\mathrm{GO}$, allowing protons diffuse on $\mathrm{GO}$ nanosheets even at higher temperature.

\section{Conclusion}

We have successfully fabricated cation-modified GO membranes by introducing $\mathrm{Al}^{3+}$ and $\mathrm{La}^{3+}$ in a $\mathrm{GO}$ suspension prior to the membrane fabrication. The intercalated cations, especially $\mathrm{La}^{3+}$, can significantly increase the proton conductivity of the membrane, possibly due to the ionic interaction between oxygen functional groups and the cations. This resulted in an increase in distance of the interlayer that functioned as a proton hopping pathway. The presence of $\mathrm{La}^{3+}$ in $\mathrm{GO}$ membranes prevented detachment of oxygen functional groups at high temperatures, as suggested by XRD, FTIR, TG-DTA, and EIS results. Accordingly, the proton conductivity was maintained even at high temperature. The findings obtained here would expand the possibility of electrochemical applications of proton-conducting GO membranes and also provide ever better performance.

Acknowledgements We thank Prof. Mitsuru Sasaki for his assistance to perform TG-DTA measurements.

Funding This work was supported in part by the JST e-ASIA collaborative research Project on functional materials, a Grant-in-Aid for the Promotion of Joint International Research (15KK0189), and a Grant-in-Aid for Scientific Research (B) (18H01835) from the Ministry of Education, Culture, Sports, Science and Technology of Japan. T. K. also acknowledges the support from Kato foundation for Promotion of Science, Japan (KJ-2822).

\section{Compliance with ethical standards}

Conflict of interest On behalf of all authors, the corresponding author states that there is no conflict of interest.

Ethical approval This article does not contain any studies involving animals performed by any of the authors.

\section{References}

1. Dimiev AM (2016) Mechanism of formation and chemical structure of graphene oxide. In: Dimiev AM, Eigler S (eds) Graphene oxide. Wiley, Hoboken, pp 36-84

2. Ogata C, Kurogi R, Awaya K, Hatakeyama K, Taniguchi T, Koinuma M, Matsumoto Y (2017) All-graphene oxide flexible solid-state supercapacitors with enhanced electrochemical performance. ACS Appl Mater Interfaces 9:26151-26160. https ://doi.org/10.1021/acsami.7b04180

3. Down MP, Rowley-Neale SJ, Smith GC, Banks CE (2018) Fabrication of graphene oxide supercapacitor devices. ACS Appl Energy Mater 1:707-714. https://doi.org/10.1021/acsaem.7b00164

4. Purkait T, Singh G, Kumar D, Singh M, Dey RS (2018) High-performance flexible supercapacitors based on electrochemically tailored three-dimensional reduced graphene oxide networks. Sci Rep. https://doi.org/10.1038/s41598-017-18593-3

5. Behling R, Valange S, Chatel G (2016) Heterogeneous catalytic oxidation for lignin valorization into valuable chemicals: what results? What limitations? What trends? Green Chem 18:1839_ 1854. https://doi.org/10.1039/C5GC03061G

6. Grigoriev S, Fateev V, Pushkarev A, Pushkareva I, Ivanova N, Kalinichenko V, Presnyakov MY, Wei X (2018) Reduced graphene oxide and its modifications as catalyst supports and catalyst layer modifiers for PEMFC. Materials 11:1405. https:// doi.org/10.3390/ma11081405

7. Majumdar B, Sarma D, Bhattacharya T, Sarma TK (2017) Graphene oxide as metal-free catalyst in oxidative dehydrogenative $\mathrm{C}-\mathrm{N}$ coupling leading to a-ketoamides: importance of dual catalytic activity. ACS Sustain Chem Eng 5:9286-9294. https:// doi.org/10.1021/acssuschemeng.7b02267

8. Kida T, Kuwaki Y, Miyamoto A, Hamidah NL, Hatakeyama K, Quitain AT, Sasaki M, Urakawa A (2018) Water vapor electrolysis with proton-conducting graphene oxide nanosheets. ACS Sustain Chem Eng 6:11753-11758. https://doi.org/10.1021/acssu schemeng.8b01998

9. Thimmappa R, Chattanahalli Devendrachari M, Shafi S, Freunberger S, Ottakam Thotiyl M (2016) Proton conducting hollow graphene oxide cylinder as molecular fuel barrier for tubular $\mathrm{H}$ 2-air fuel cell. Int J Hydrogen Energy 41:22305-22315. https:// doi.org/10.1016/j.ijhydene.2016.08.057

10. Tateishi H, Hatakeyama K, Ogata C, Gezuhara K, Kuroda J, Funatsu A, Koinuma $M$, Taniguchi T, Hayami S, Matsumoto $Y$ (2013) Graphene oxide fuel cell. J Electrochem Soc 160:F1175F1178. https://doi.org/10.1149/2.008311jes

11. Jang HR, Vinothkannan M, Kim AR, Yoo DJ (2018) Constructing proton-conducting channels within sulfonated(poly arylene ether ketone) using sulfonated graphene oxide: a nano-hybrid membrane for proton exchange membrane fuel cells: constructing proton-conducting channels within sulfonated (poly arylene ether ketone). Bull Korean Chem Soc 39:715-721. https://doi. org/10.1002/bkcs.11459

12. Hatakeyama K, Islam MS, Michio K, Ogata C, Taniguchi T, Funatsu A, Kida T, Hayami S, Matsumoto Y (2015) Super proton/electron mixed conduction in graphene oxide hybrids by intercalating sulfate ions. J Mater Chem A 3:20892-20895. https://doi. org/10.1039/C5TA05653E

13. Hatakeyama K, Karim MR, Ogata C, Tateishi H, Funatsu A, Taniguchi T, Koinuma M, Hayami S, Matsumoto Y (2014) Proton conductivities of graphene oxide nanosheets: single, multilayer, and modified nanosheets. Angew Chem Int Ed 53:6997-7000. https ://doi.org/10.1002/anie.201309931

14. Wenzheng Y, Yu T, Graham N (2017) Development of a stable cation modified graphene oxide membrane for water treatment. 2D Mater 4:045006

15. Mo Y, Zhao X, Shen Y (2016) Cation-dependent structural instability of graphene oxide membranes and its effect on membrane separation performance. Desalination 399:40-46. https ://doi.org/10.1016/j.desal.2016.08.012

16. Xu X-L, Lin F-W, Du Y, Zhang X, Wu J, Xu Z-K (2016) Graphene oxide nanofiltration membranes stabilized by cationic porphyrin for high salt rejection. ACS Appl Mater Interfaces 8:1258812593. https://doi.org/10.1021/acsami.6b03693 
17. Huang $H$, Song $Z$, Wei $N$, Shi L, Mao Y, Ying $Y$, Sun L, Xu Z, Peng $X$ (2013) Ultrafast viscous water flow through nanostrand-channelled graphene oxide membranes. Nat Commun 4:2979

18. Amirov RR, Shayimova J, Nasirova Z, Dimiev AM (2017) Chemistry of graphene oxide. Reactions with transition metal cations. Carbon 116:356-365. https://doi.org/10.1016/j.carbo n.2017.01.095

19. Amirov RR, Shayimova J, Nasirova Z, Solodov A, Dimiev AM (2018) Analysis of competitive binding of several metal cations by graphene oxide reveals the quantity and spatial distribution of carboxyl groups on its surface. Phys Chem Chem Phys 20:2320-2329. https://doi.org/10.1039/C7CP07055A

20. Hjalmarsson P, Søgaard M, Hagen A, Mogensen M (2008) Structural properties and electrochemical performance of strontium- and nickel-substituted lanthanum cobaltite. Solid State Ion 179:636-646. https://doi.org/10.1016/j.ssi.2008.04.026

21. Hrovat M, Bernik S, Kuscer D, Holc J, Katsarakis N, Reichmann $\mathrm{K}$ (1996) Characterisation of LaNi\{sub 1\}-xCo\{sub x\}O\{sub 3$\}$ as a possible SOFC cathode material. Solid State Ion. https://doi. org/10.1016/0167-2738(95)00224-3

22. Chou C-Y, Kaurav N, Kuo Y-K, Kuo D-H (2008) Electrical properties of $\mathrm{A} / \mathrm{B}$-site substituted $\mathrm{Ni}$-deficient $\mathrm{La}\left(\mathrm{Ni}_{0.6} \mathrm{Fe}_{0.3}\right) \mathrm{O}_{3}$ perovskites with $\mathrm{A}=\mathrm{Ag}^{+}, \mathrm{Pb}^{2+}, \mathrm{Nd}^{3+}$ and $\mathrm{B}=\mathrm{Mn}^{3+}, \mathrm{Ga}^{3+}$. J Appl Phys. https ://doi.org/10.1063/1.2924424

23. Miyamoto A, Kuwaki Y, Sano T, Hatakeyama K, Quitain A, Sasaki M, Kida T (2017) Solid electrolyte gas sensor based on a protonconducting graphene oxide membrane. ACS Omega 2:29943001. https://doi.org/10.1021/acsomega.7b00239

24. Mission EG, Quitain AT, Sasaki M, Kida T (2017) Synergizing graphene oxide with microwave irradiation for efficient cellulose depolymerization into glucose. Green Chem 19:3831-3843. https://doi.org/10.1039/C7GC01691C

25. Chen F, Liu P (2011) Conducting polyaniline nanoparticles and their dispersion for waterborne corrosion protection coatings. ACS Appl Mater Interfaces 3:2694-2702. https://doi. org/10.1021/am200488m
26. Guo X, Du K, Wang Y, Shao Y, Wang F (2012) A new nanoparticle penetrant used for plasma electrolytic oxidation film coated on AZ31 Mg alloy in service environment. Surf Coat Technol 206:4833-4839. https://doi.org/10.1016/j.surfcoat.2012.05.063

27. Lu F, Song B, He P, Wang Z, Wang J (2017) Electrochemical impedance spectroscopy (EIS) study on the degradation of acrylic polyurethane coatings. RSC Adv 7:13742-13748. https ://doi.org/10.1039/C6RA26341K

28. Johra FT, Lee J-W, Jung W-G (2014) Facile and safe graphene preparation on solution based platform. J Ind Eng Chem 20:2883-2887. https://doi.org/10.1016/j.jiec.2013.11.022

29. Ates M (2011) Review study of electrochemical impedance spectroscopy and equivalent electrical circuits of conducting polymers on carbon surfaces. Prog Org Coat 71:1-10. https:// doi.org/10.1016/j.porgcoat.2010.12.011

30. Gong Y, Li D, Fu Q, Pan C (2015) Influence of graphene microstructures on electrochemical performance for supercapacitors. Prog Nat Sci Mater Int 25:379-385. https://doi.org/10.1016/j. pnsc.2015.10.004

31. Fasmin F, Srinivasan R (2017) Review-nonlinear electrochemical impedance spectroscopy. J Electrochem Soc 164:H443H455. https://doi.org/10.1149/2.0391707jes

32. Hatakeyama K, Tateishi H, Taniguchi T, Koinuma M, Kida T, Hayami S, Yokoi H, Matsumoto Y (2014) Tunable graphene oxide proton/electron mixed conductor that functions at room temperature. Chem Mater 26:5598-5604. https://doi.org/10.1021/ cm502098e

Publisher's Note Springer Nature remains neutral with regard to jurisdictional claims in published maps and institutional affiliations. 